Estudios Fronterizos, vol. 10, núm. 20, julio-diciembre 2009, pp. 9-45

\title{
Militarización de la frontera e inmigración ilegal: los jornaleros tamaulipecos
}

\author{
Simón Pedro Izcara Palacios*
}

\begin{abstract}
Resumen. Tamaulipas presenta una larga tradición de emigración de su población rural a los Estados Unidos en busca de empleos agrarios. Hasta los años ochenta los trabajadores indocumentados tamaulipecos cruzaban la frontera sin muchas dificultades. Sin embargo, a partir de los años noventa, como resultado de una política de contención de la emigración ilegal centrada únicamente del lado de la oferta, el cruce de la frontera se torna más problemático, y los inmigrantes se ven obligados a contratar de forma generalizada los servicios de "polleros". Este artículo analiza el impacto de la militarización de la frontera en la emigración irregular de trabajadores rurales tamaulipecos que buscan empleos agrarios en Estados Unidos.

Palabras clave: "Polleros", inmigración ilegal, jornaleros.
\end{abstract}

Abstract. Tamaulipas presents a long tradition of rural migration to the United States in search of farm employment. Until the eighties Tamaulipas' undocumented workers crossed the border easily. However, from the nineties, as a result of a restrictive migration policy centered exclusively on the "supply-side" to cross the border has become intricate. As a result, most part of immigrants is using the services of "smuggles". This paper analyses the impact of the militarization of the frontier on the emigration of Tamaulipas' illegal rural workers seeking for farm jobs in the United States.

Key words: Smugglers, illegal immigration, farm workers.

Artículo recibido el 11 de agosto de 2008 Segunda versión recibida el 10 de diciembre de 2008 Tercera versión recibida el 17 de marzo de 2009

Artículo aprobado el 20 de marzo de 2009

\footnotetext{
* Profesor de Sociología Rural, Unidad Académica Multidisciplinaria de Ciencias, Educación y Humanidades, Universidad Autónoma de Tamaulipas. Correo electrónico: sp_izcara@yahoo.com; sizcara@uat.edu.mx
} 


\section{Introducción $^{1}$}

Por más de un siglo los empresarios agrarios estadounidenses han buscado incrementar la rentabilidad de sus explotaciones mediante el empleo de mano de obra foránea, disciplinada y no sindicalizada. La ley migratoria norteamericana ha contribuido a crear un ambiente favorable para el desarrollo del empleo irregular en la agricultura al colocar al inmigrante indocumentado y al empresario agrario en una posición asimétrica. Al primero le niega cualquier tipo de derecho laboral y al último le exceptúa de toda responsabilidad penal. A comienzos de los años cincuenta la "enmienda texana" permitía a los empresarios agrarios dar empleo a inmigrantes indocumentados. Tres décadas más tarde la Ley Simpson-Mazzoli establecía mecanismos que permitían a los empleadores evitar las sanciones por contratar trabajadores ilegales.

Los jornaleros tamaulipecos siempre han sido muy apreciados por los empresarios agrarios estadounidenses debido a su experiencia en la realización de actividades agrarias muy exigentes y su valía para el trabajo del campo. Éstos han emigrado tanto de forma indocumentada como por medio de programas de trabajadores huéspedes. Hasta los años sesenta y setenta, e incluso durante los ochenta, los trabajadores indocumentados tamaulipecos cruzaban la frontera sin mayores dificultades. Es a partir de la década del noventa, como resultado de una política de contención de la emigración irregular centrada únicamente del lado de la oferta, cuando el cruce de la frontera se torna más problemático y los inmigrantes se ven obligados a contratar de forma generalizada los servicios de "polleros". ${ }^{2}$ La militarización de la frontera hace que el costo económico y social de cruzar a los Estados Unidos se incremente de modo considerable, y que los jornaleros

\footnotetext{
${ }^{1}$ Quisiera expresar mi agradecimiento tanto a Conacyt, a través del proyecto "Migrantes estacionales de Tamaulipas en la agricultura de Estados Unidos", $\mathrm{N}^{\circ}$ 52636, como a la Universidad Autónoma de Tamaulipas, a través del proyecto "Migrantes rurales tamaulipecos y el programa H-2A de trabajadores huéspedes" (Convenio número: UAT-07-8-SOC-0114), por el apoyo recibido para la realización de esta investigación.

${ }^{2}$ En este artículo los términos "agente facilitador del cruce de la frontera", "coyote" y "pollero" son utilizados de forma indistinta.
} 
tamaulipecos se muevan a través de rutas cada vez más extensas en busca de salarios más elevados, al mismo tiempo que permanecen en el país del norte por espacios temporales cada vez más prolongados. La criminalización de la emigración irregular también la ha desincentivado y ha tornado más atractivos los programas de trabajadores huéspedes, aunque la participación de los empleadores en el tráfico de indocumentados ha elevado la oferta de mano de obra indocumentada en el sector agrario estadounidense.

Este artículo analiza el impacto de la militarización de la frontera en la emigración irregular de trabajadores rurales tamaulipecos que buscan empleos agrarios en Estados Unidos. En primer lugar se examina la pérdida poblacional del medio rural tamaulipeco como consecuencia de la emigración. En segundo lugar se describe el proceso de militarización de la frontera. A continuación se estudia el aumento de las tarifas pagadas a los "polleros" y el desplazamiento de los trabajadores rurales tamaulipecos a través de rutas migratorias más complejas. Después se examina cómo una mayor vigilancia de la frontera ha desincentivado la emigración irregular e incrementado el atractivo del programa de visas H-2A para trabajadores huéspedes; finalmente, se señala cómo un inadecuado monitoreo de los lugares de trabajo favorece el crecimiento de la inmigración irregular.

\section{Nota metodológica}

Esta investigación está cimentada en el uso de fuentes de información cuantitativa y cualitativa. En el proceso de selección de los entrevistados se optó por utilizar un muestreo estratificado intencional (Izcara Palacios, 2007:25 y 26), y la recopilación de información se extendió hasta llegar a una saturación del campo de diferencias en la producción discursiva de los hablantes (Coyne, 1997:629). Un total de 50 trabajadores rurales tamaulipecos de edades comprendidas entre $23 \mathrm{y}$ 67 años de edad, con experiencia de haber cruzado ilegalmente la frontera y haber sido empleados en la agricultura, fueron entrevistados en 37 comunidades rurales de 13 municipios tamaulipecos representativos de la diversidad geográfica de este estado. Las entrevistas fueron realizadas entre los meses de marzo de 2007 y junio de 2008. Se persi- 
guió que un tercio de los informantes fuesen menores de 30 años de edad, otro tercio tuviesen edades comprendidas entre 30 y 45 años, y otro tercio fuesen mayores a 45 años. Con esta división por edades se pretendía subrayar el predominio de trabajadores jóvenes en esta actividad; pero al mismo tiempo se quería rescatar el testimonio de trabajadores de mayor edad que en décadas pasadas emigraron a Estados Unidos, con objeto de recuperar un dibujo diacrónico de la presencia de trabajadores tamaulipecos en la agricultura estadounidense.

Por otra parte, entre los meses de octubre de 2007 y enero de 2009 también se realizaron entrevistas en profundidad a siete trabajadores rurales tamaulipecos que trabajaron en Estados Unidos con visas H2A y a seis agentes facilitadores del cruce de la frontera, que fueron utilizadas en la elaboración de este artículo.

\section{La emigración de jornaleros tamaulipecos a Estados Unidos}

En México la liberalización del sector agrario y la subsiguiente supresión de los controles de precios y erosión de los subsidios a los insumos y al crédito han contribuido a acelerar la emigración rural (Andreas, 1996:61 y 1998:609; Mendoza Cota, 2006:139; Boucher et al., 2007:7). Un análisis de los datos de la Encuesta Sobre Migración de la Frontera Norte de México revela a partir de 1998 un fuerte crecimiento de los trabajadores migratorios temporales de procedencia rural debido a una creciente incapacidad del sector agrario de proporcionar empleo estable a la población rural. Igualmente, en el medio rural tamaulipeco la emigración a Estados Unidos en busca de empleos agrarios aparece unida a la crisis de la agricultura (Izcara Palacios, 2006:85). En este sentido, Alfonso se quejaba de la emigración de los varones jóvenes del ejido hacia Estados Unidos en busca de empleo mejor remunerado, y achacaba el deterioro de la agricultura a la falta de apoyos gubernamentales al sector:

Casi ni hay hombres para trabajar la tierra [...] el gobierno debería dar apoyos para que mejor trabajen en el campo en lugar de irse para allá. 
Aunque durante las últimas dos décadas algunas de las producciones más importantes (el sorgo, la caña de azúcar, la naranja y la soya) han crecido, otras, que en el año 1985 ocupaban los primeros lugares en cuanto a superficie sembrada (el maíz, el cártamo y el frijol), han descendido en $58 \%, 72 \%$ y $96 \%$ respectivamente. ${ }^{3}$ Como consecuencia, las oportunidades económicas de la población joven que reside en el medio rural tamaulipeco se han contraído. Es por ello que el número de trabajadores locales que emigran al país del norte en busca de mejores condiciones sociolaborales ha crecido durante los últimos años.

Por otra parte, el acceso a un mercado de trabajo caracterizado por salarios más elevados ha restado atractivo al mercado laboral local. Los retornados difícilmente se acomodan a unos salarios que son hasta 10 veces inferiores a los jornales estadounidenses (Izcara Palacios, 2006:105), y continúan emigrando, a la vez que fomentan la emigración de otros paisanos (Izcara Palacios, 2009b:18). Esto conduce a un vaciamiento de la población activa rural. Es por ello que los sectores más demandantes de mano de obra (los cítricos en la zona centro, ${ }^{4}$ la caña de azúcar en el sur ${ }^{5}$ y las hortalizas en el sureste del estado ${ }^{6}$ ) se tornan cada vez más dependientes del empleo de trabajadores migratorios. Como resultado, el medio rural tamaulipeco presenta la paradoja de constituir un centro receptor y expulsor de jornaleros migratorios. La llegada estacional a Tamaulipas de miles de trabajadores, procedentes de Veracruz y San Luis Potosí, en busca de salarios más elevados que en sus lugares de origen (Andrade Rubio, 2008) deprime las oportunidades económicas de los jornaleros locales, presiona a la baja los salarios y fomenta la emigración (Izcara Palacios y Andrade Rubio, 2006 y 2007). Asimismo, la emigración de trabajadores locales favorece la inmigración de jornaleros procedentes de otros estados y crea una espiral que se autorrefuerza.

El cuadro 1 muestra la pérdida poblacional del medio rural tamaulipeco como consecuencia de la emigración. Todos los municipios tamaulipecos, sin excepción, han sufrido tasas negativas de

\footnotetext{
${ }^{3}$ Datos facilitados por la Secretaría de Desarrollo Rural.

${ }^{4}$ Principalmente los municipios de Hidalgo, Güémez y Padilla.

${ }^{5}$ Principalmente los municipios de Xicoténcatl, Mante y Gómez Farías.

${ }^{6}$ Principalmente los municipios de González y Altamira.
} 


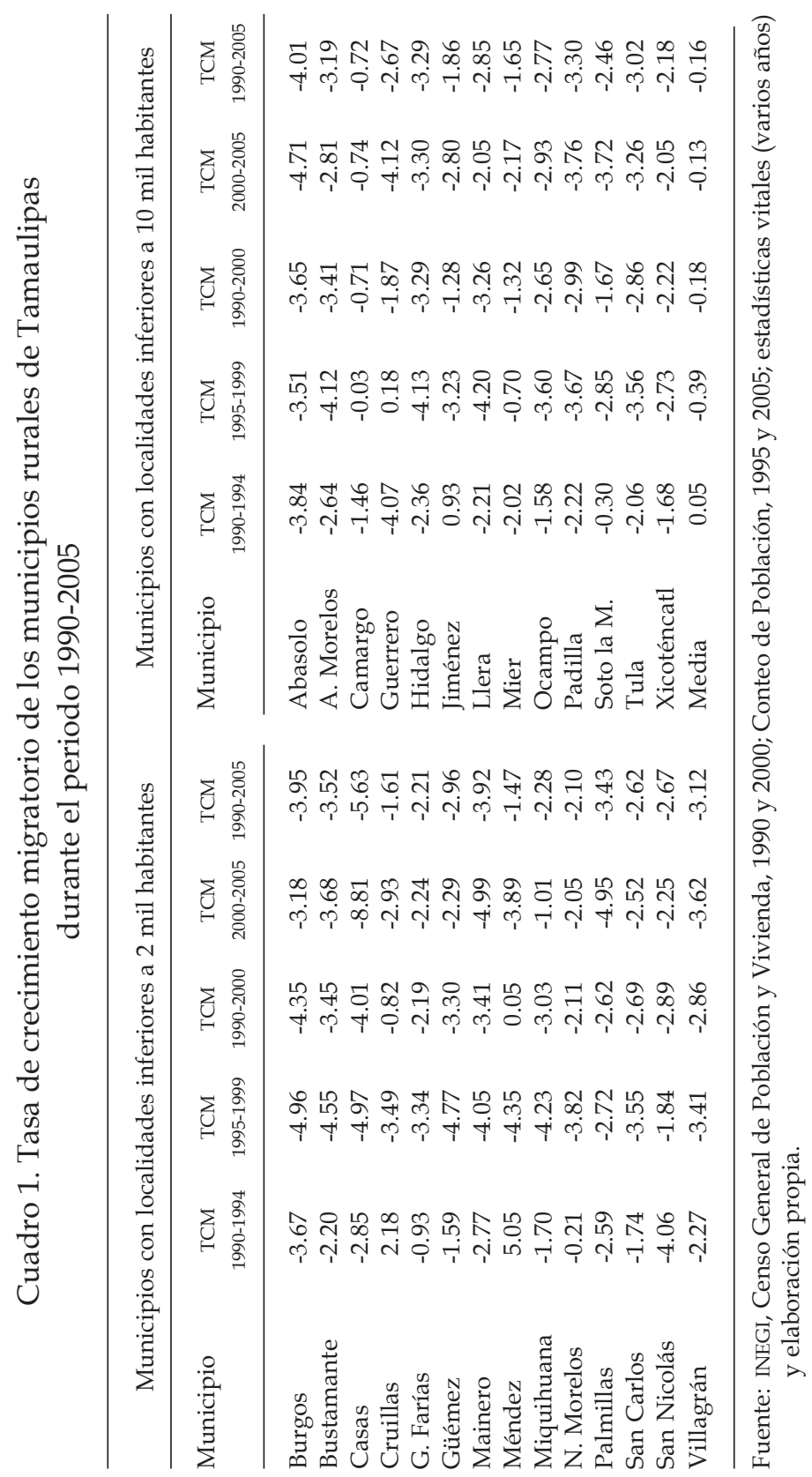


crecimiento migratorio entre los años 1990 y 2005, que en la mayor parte de los casos han supuesto una pérdida anual de población comprendida entre 2 y 5 por ciento.

Un análisis de los datos del último Conteo de Población permite inferir que se trata de una pérdida de población joven. La escasez de oportunidades económicas en el medio rural y el escaso atractivo de los empleos locales han conducido a una distorsión de la pirámide demográfica, que se estrecha en el centro y se ensancha en la cúspide (Izcara Palacios, 2009a:79). El elevado índice de dependencia de los municipios rurales tamaulipecos hace referencia a una pérdida de población activa. En municipios como Bustamante, Miquihuana o Palmillas el número de habitantes económicamente dependientes casi iguala a la población potencialmente activa (véase cuadro 2). Como indicaba Alejandro:

Hay temporadas en que no hay muchachos aquí en el ejido, hay puros chavitos, chavalillos; aquí nomás empiezan a trabajar, así que uno ya tenga papeles, que sea mayor, y ya ve la manera de salir a otro lugar a buscar trabajo, la mayoría se van a trabajar allá, al otro lado.

La figura 1, que muestra que el tamaño poblacional explica $28 \%$ de la varianza del índice de dependencia, permite apreciar más claramente el elevado peso de los grupos sociales económicamente dependientes en el medio rural tamaulipeco.

Por otra parte, un análisis de la razón de masculinidad indica que esta emigración de población joven no es uniforme en función del género. ${ }^{7}$ En algunos municipios (Burgos, Gómez Farías, Palmillas, San Nicolás, Abasolo, Antiguo Morelos, Jiménez, Llera, Ocampo, Tula y Xicoténcatl) se da una sobreemigración masculina, y en otros (Casas, Miquihuana, Villagrán, Camargo, Guerrero) emigran más las mujeres (véase cuadro 3). ${ }^{8}$

\footnotetext{
${ }^{7}$ En poblaciones de alta emigración una razón de masculinidad inferior a 100 es indicativo de una emigración de varones superior a la de mujeres, y viceversa si es superior a 100.

${ }^{8}$ En los restantes municipios se producen diferencias de género entre los diferentes grupos de edad.
} 


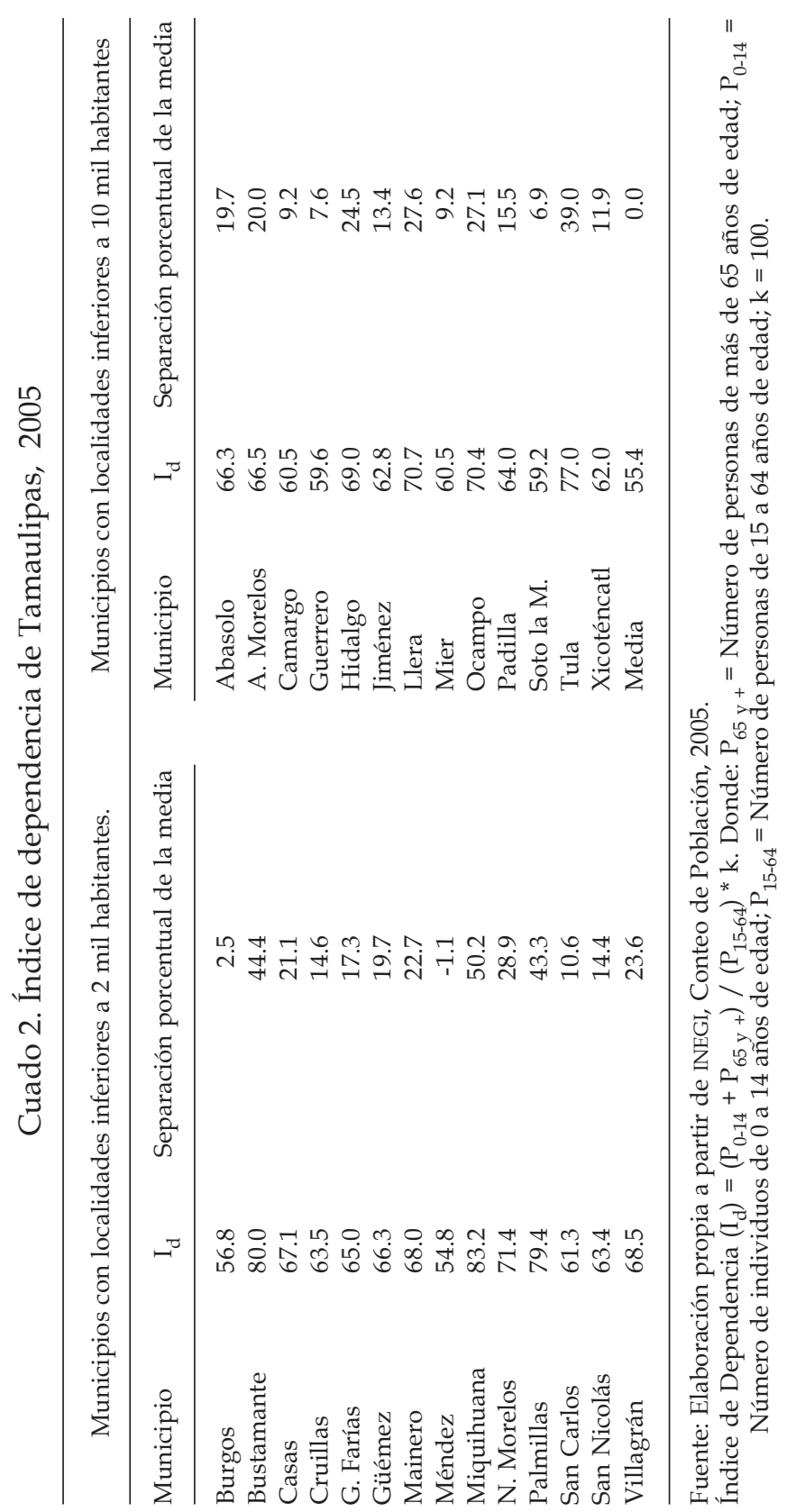


Figura 1.

Ecuación de regresión entre el tamaño poblacional y el índice de dependencia (Municipios de Tamaulipas, año 2005)

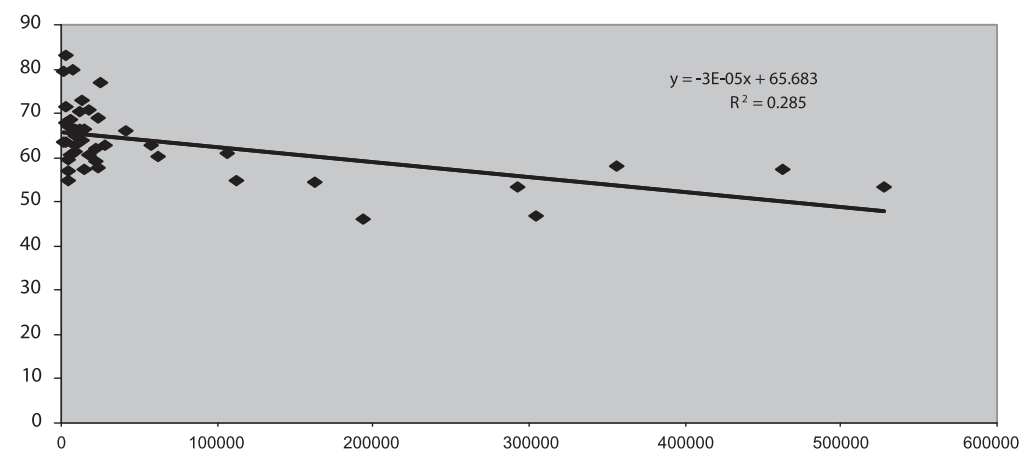

Fuente: Elaboración propia a partir de INEGI. Conteo de Población, 2005.

La pérdida de población activa del medio rural tamaulipeco se atribuye a la emigración internacional, y es contemplada como un proceso de vaciado de la población masculina. Como decía Torres: "Aquí casi todos los hombres vamos a trabajar para allá". La expresión de Francisco: "Se va toda la comunidad [...] con decirte que aquí se quedan puras mujeres y niños", muestra el sentir de muchos de los entrevistados, que contemplan el medio rural tamaulipeco como un área donde los varones jóvenes emigran a los Estados Unidos mientras las mujeres y los niños se quedan. Los datos del cuadro 4, que muestran el porcentaje de residentes rurales que cinco años atrás vivían en el extranjero u otro estado, confirman esta percepción.

Por lo tanto, la única explicación para los datos del cuadro 3, que implica que son tanto las mujeres como los varones los que emigran, es que mientras los últimos emigran más hacia espacios más lejanos (Estados Unidos y otros estados), las mujeres rurales se desplazan más hacia áreas más cercanas: las zonas urbanas tamaulipecas. La mayor parte de los núcleos urbanos tamaulipecos han crecido debido a la emigración durante el periodo 1990-2005 (véase cuadro 5). Por lo tanto, la lectura de la razón de masculinidad es inversa. Cuando ésta 


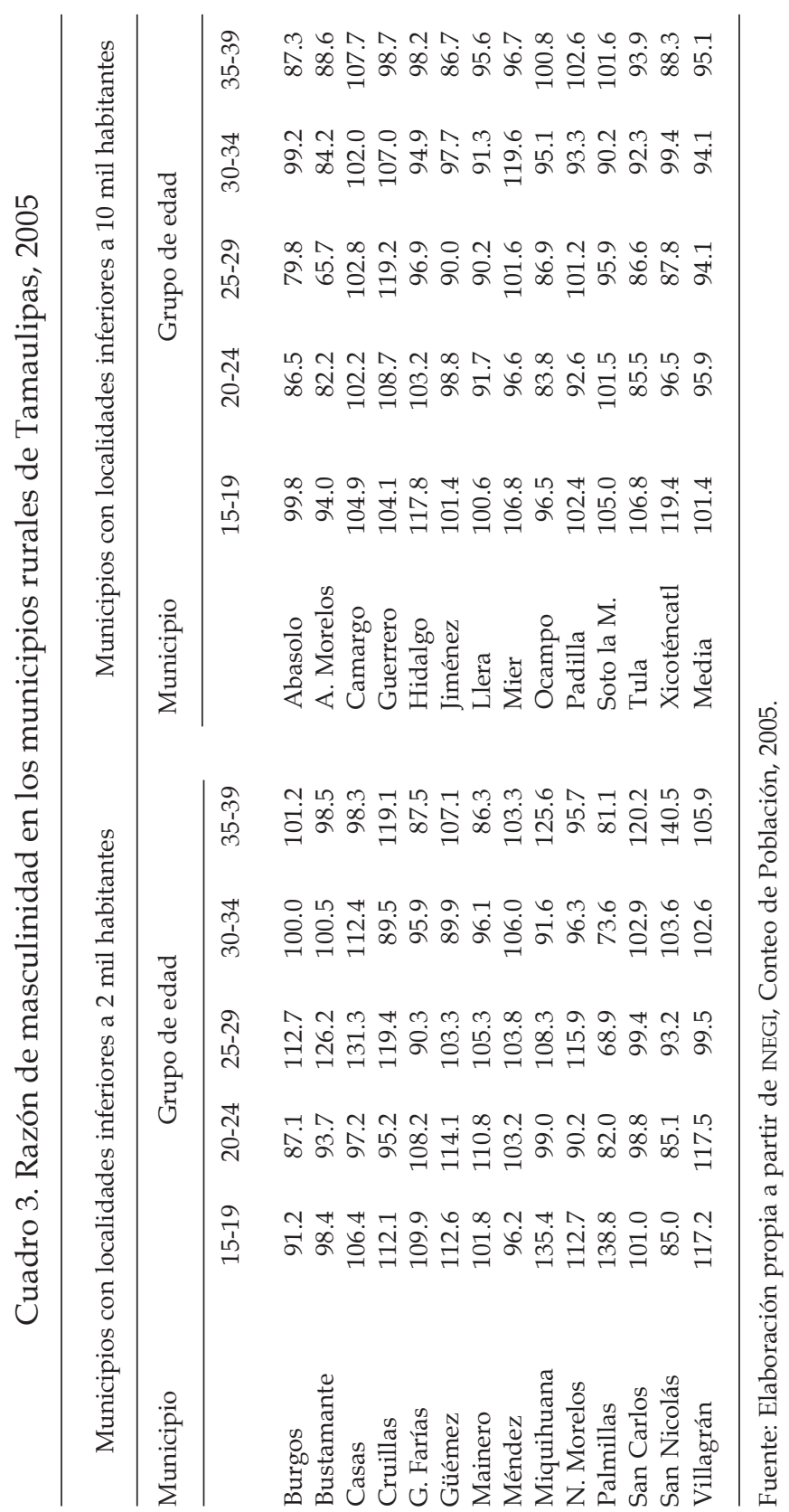




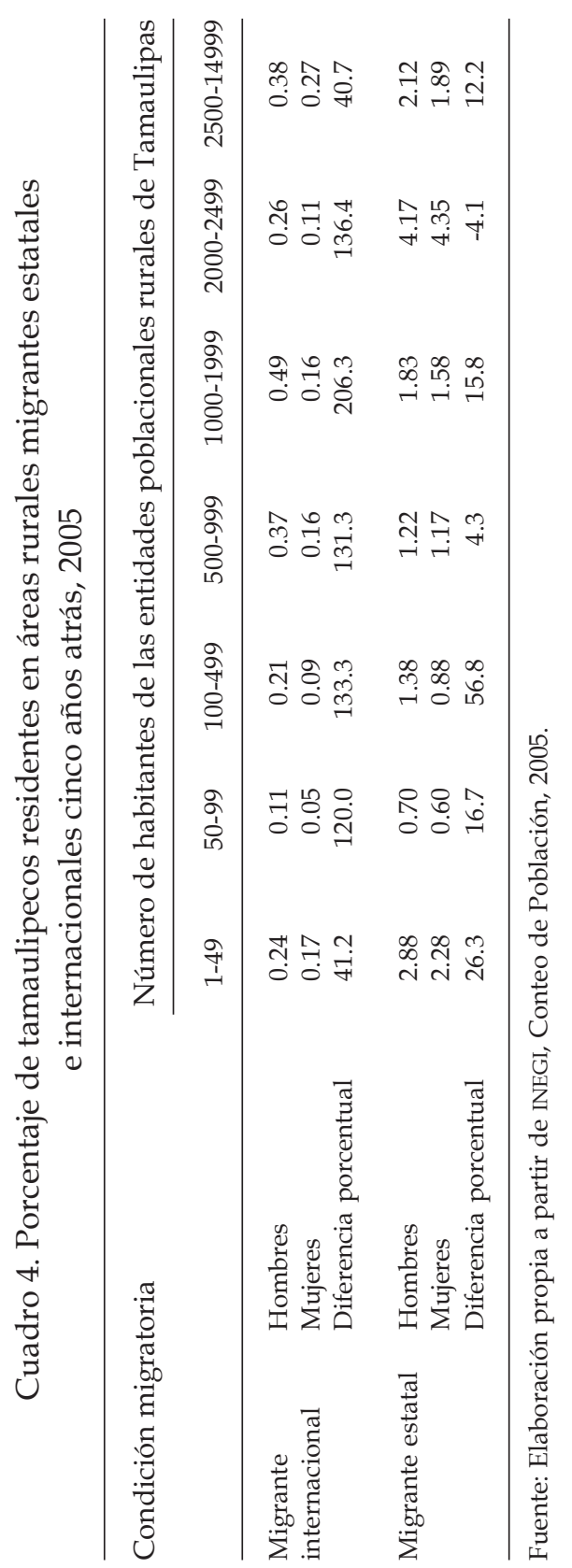




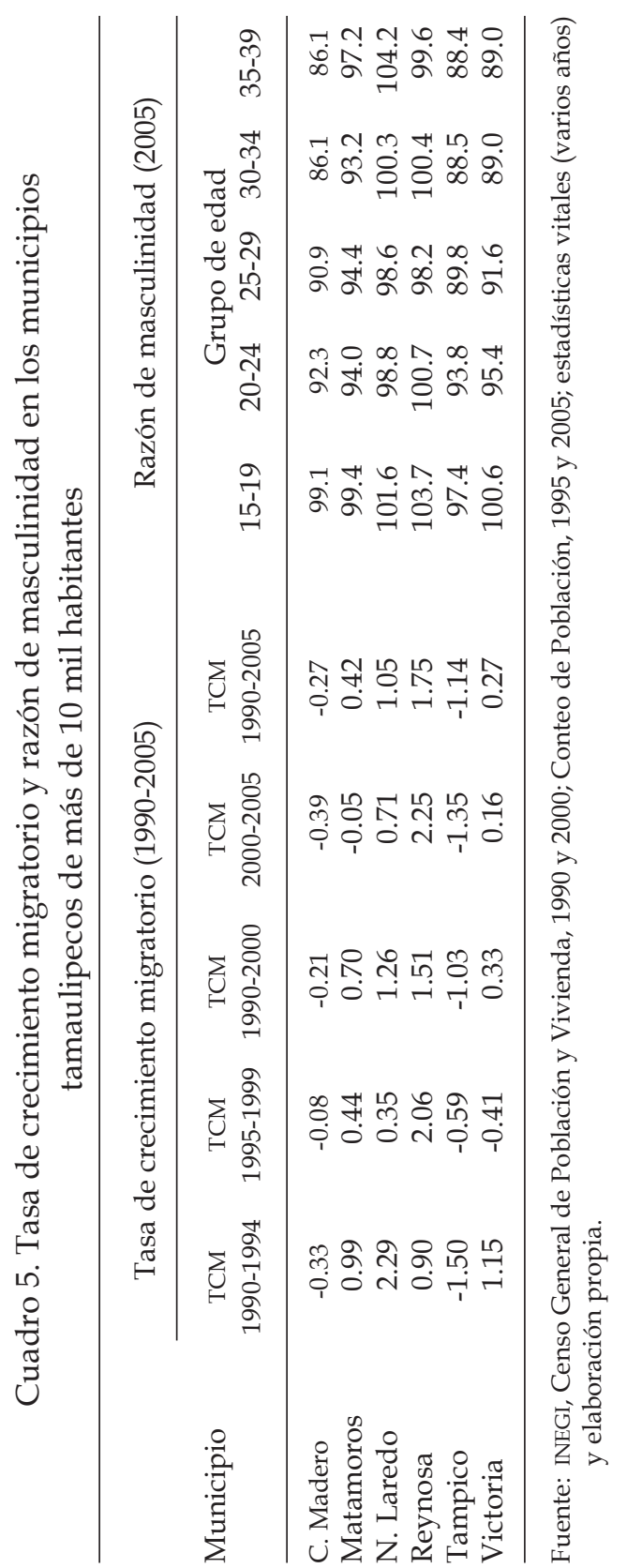


es inferior a 100 implica que estas poblaciones están recibiendo una inmigración feminizada. ${ }^{9}$

\section{El proceso de militarización de la frontera}

El incremento del número de inmigrantes indocumentados en Estados Unidos conduce a mediados de los años ochenta a un cambio en la política migratoria estadounidense. En noviembre de 1986 fue aprobada la Ley de Reforma y Control de la Inmigración (IRCA). El objetivo de esta ley era legalizar a la población extranjera indocumentada que vivía en Estados Unidos desde 1982, y reducir la inmigración subrepticia a partir del establecimiento de sanciones a los empleadores que contrataban inmigrantes indocumentados y mediante un más riguroso y eficiente control de las fronteras (Martin, 1990; Corona Vázquez, 1993:221). La oferta de legalización de indocumentados ofrecida por la ley hizo que millones de trabajadores adquiriesen la residencia permanente en Estados Unidos (Verduzco Igartúa, 1995:582; Velasco Ortiz, 2002:354 y 355), de modo que este programa de legalización masiva lejos de frenar el flujo migratorio irregular (Orrenius y Zavodny, 2001), contribuyó a reforzar las "redes migratorias" e intensificar los flujos migratorios, porque aquellas personas amnistiadas, ahora con una mayor seguridad y estabilidad laboral, tuvieron más posibilidades de promover la migración de sus amigos y parientes residentes en México (Arrollo Alejandre et al., 1991:130; Stephen, 2002:96).

En los años noventa el crecimiento de la inmigración indocumentada se tradujo en el esparcimiento de un sentimiento antiinmigración en Estados Unidos, cuya manifestación más palpable fue la aprobación en 1994 de la Proposición 187 en California, ${ }^{10}$ la cual negaba a los inmigrantes indocumentados el acceso a la sanidad, educación y otros

\footnotetext{
${ }^{9}$ Tampico perdió más de $1 \%$ anual de su población durante este periodo debido a la emigración. Sin embargo, una razón de masculinidad tan baja no se explicaría sólo por una emigración muy masculinizada. Únicamente una inmigración feminizada explica ese desequilibrio de géneros tan acusado.

${ }^{10}$ La Proposición 187 sería revocada varios años después al ser declarada anticonstitucional por las cortes federales (Cornelius, 2007:254).
} 
servicios sociales. Dos años después, en septiembre de 1996, apareció la Ley de Reforma de la Inmigración Ilegal y de la Responsabilidad del Inmigrante (IIRIRA). Esta ley tenía como objetivo primordial poner freno a la inmigración indocumentada a partir de un férreo control de las fronteras (Valdivia Durán, 2001:145). La vigilancia de la frontera se refuerza con más patrulleros, con la construcción de más muros y bardas a lo largo de la misma, y con la adquisición de tecnología militar para detectar y detener a los inmigrantes indocumentados, ${ }^{11}$ al mismo tiempo que se endurecen las penas contra los traficantes de personas (Andreas, 1999:592).

Se tomó la decisión de concentrar la vigilancia en cuatro segmentos de la frontera suroeste. En 1993 se desarrolla en El Paso la operación "Mantengan la Línea"; 12 un año más tarde surge en San Diego la operación "Guardián"; el año siguiente nace en Arizona la operación "Salvaguarda", y dos años después, en 1997, se inicia en Texas la operación "Río Grande". Estas operaciones aparecerán centradas en una mayor vigilancia de las áreas más pobladas, utilizadas tradicionalmente por tres cuartas partes de los inmigrantes indocumentados que ingresaban en Estados Unidos (Cornelius, 2007:256; Marroni y Alonso Meneses, 2006:8). Así, en los años noventa Estados Unidos inicia la implementación de una nueva estrategia de control de la emigración denominada "Prevención por medio de disuasión" (Andreas, 1999:596; Zúñiga y Leite, 2007:174), consistente en un progresivo reforzamiento de la custodia de la frontera. Es decir, se produce de manera progresiva una militarización de la frontera (Marroni y Alonso Meneses, 2006:9) con el objetivo de desincentivar la inmigración irregular. Sin embargo, el resultado de esta estrategia no fue una reducción de los flujos migratorios, sino un desvío de los mismos hacia zonas desérticas de más difícil accesibilidad, con un incremento exponencial del costo económico y social de la emigración (Andreas, 2003:3). Así, entre 1996 y 2003 la probabilidad de morir cruzando la frontera se multiplicó casi por ocho (Izcara Palacios, 2006:96).

${ }^{11}$ Tecnologías y equipos designados para propósitos militares (detectores magnéticos de pisadas, sensores infrarrojos de cuerpos, sistemas de fotoidentificación, etc.) están siendo utilizados en el control de la frontera (Andreas, 1996:63; 1999:592).

${ }^{12}$ Denominada en un primer momento "Bloqueo". 
Peter Andreas (1999:598 y 2003:3) habla de un fracaso exitoso de esta estrategia de control fronterizo. El fracaso de la misma se evidencia en el crecimiento progresivo de la inmigración irregular; mientras que el éxito de ésta se refleja en la desviación de los cruces fronterizos fuera de la vista de las poblaciones urbanas. Como señala el autor, esta estrategia está siendo enormemente contraproducente, ya que ha contribuido a prolongar las estancias en Estados Unidos y a fortalecer las redes del tráfico de indocumentados (Andreas, 1998:82).

Los sucesos del 11 de septiembre precipitaron el resurgimiento del sentimiento antiinmigratorio que reclama la implementación de políticas migratorias más restrictivas (Pérez Duperou, 2007:161; Tuirán, 2006:164). El 16 de diciembre de 2005 la Cámara baja aprobó el Proyecto de Ley HR4447 dirigido básicamente a reforzar la seguridad fronteriza a través de: 1 . la criminalización del ingreso y estadía indocumentada; 2. la imposición de sanciones a los facilitadores de la entrada y permanencia en Estados Unidos y 3. el levantamiento de un muro a lo largo de 1116 kilómetros (Tuirán, 2006:164 y 2007:118; Pérez Duperou, 2007:169). Finalmente, el 16 de mayo de 2006 el anuncio del entonces presidente George Bush de enviar seis mil efectivos de la Guardia Nacional a la frontera con México fortaleció el proceso de militarización de la frontera (Green, 2007:153; Cabrera, 2007:315; Tuirán, 2006:166).

El reforzamiento de la vigilancia fronteriza no ha logrado detener la inmigración irregular (Hannson et al., 2002). Además, cerca de la mitad de los inmigrantes indocumentados que residen en Estados Unidos ingresaron legalmente, quedándose en el país cuando sus permisos expiraron (Tuirán, 2007:123). Por lo tanto, el efecto de un mayor reforzamiento de los controles fronterizos ha sido una disuasión de la salida, no de la entrada a Estados Unidos (Zúñiga y Leite, 2007:179; Reyes, 2001 y 2004), y ha producido una elevación paulatina del número de inmigrantes indocumentados que residen en el país. Es más, en la actualidad el grueso de la emigración de mexicanos a Estados Unidos es no autorizada. En este sentido, 85\% de los mexicanos que ingresaron a Estados Unidos en los cinco primeros años de este siglo y residían en este país en marzo de 2005 eran indocumentados (Tuirán, 2007:112). 


\section{El incremento del coste económico de cruzar la frontera}

El endurecimiento de los controles fronterizos no se ha traducido en una merma de la probabilidad de éxito en cruzar la frontera de forma irregular. Algunos estudios señalan que en los últimos años ha disminuido la probabilidad de aprehensión de los inmigrantes al cruzar la frontera (Tuirán, 2007:123), resultado de un incremento de la demanda de los servicios de "polleros" (Zúñiga y Leite, 2007:176). Asimismo, el costo de contratar a estos "agentes", que facilitan el cruce de la frontera y el internamiento en territorio estadounidense, se ha elevado sustancialmente; hasta 10 veces en las dos últimas décadas (Tuirán, 2007:113; Cabrera, 2007:314).

Como puede apreciarse en el cuadro 6, durante los años ochenta un migrante tamaulipeco debía trabajar algo más de una semana en la agricultura, entre 62 y 73 horas, para recuperar el dinero invertido en pagar al "coyote"; en los años noventa este periodo se eleva a tres semanas, entre 97 y 136 horas, y a más de un mes en los últimos años. Por otra parte, si se tiene en cuenta que el inmigrante puede tardar varias semanas en encontrar trabajo, y que además debe dedicar una parte de su salario al pago del alojamiento, la alimentación y otros gastos, se puede concluir que éste debe dedicar actualmente casi todos los ahorros reunidos durante los dos primeros meses de estancia en Estados Unidos para cubrir el pago realizado al "pollero". Como destacaba Víctor:

Como en un mes sacas eso [lo invertido en cruzar]; pero, hay que cooperarse para comprar la papa, o sea el mandado; por eso me tardé más en pagarles el dinero.

Otro aspecto importante que refleja el cuadro 6 es un crecimiento elevado de los honorarios cobrados por los "polleros" hasta el año 2001, y un freno del aumento de éstos durante los últimos seis años. Esto significa que se ha llegado a un límite máximo que puede pagar el indocumentado, a través del endeudamiento o por medio del financiamiento de fuentes en Estados Unidos. Por lo tanto, aunque el riesgo y la dificultad de cruzar la frontera se han incrementado, los 


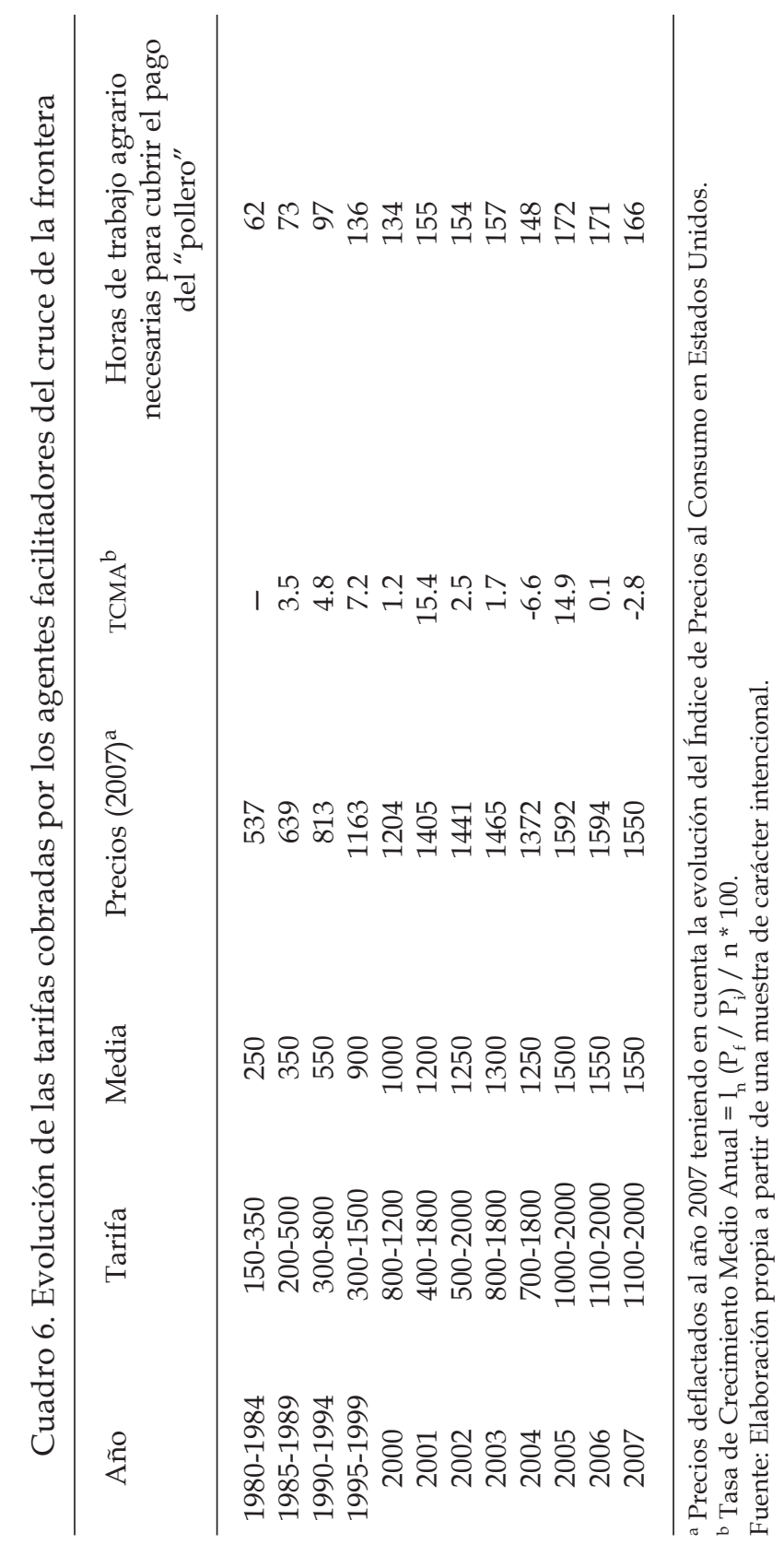


"polleros" tamaulipecos deben ofrecer unos precios competitivos para no perder su mercado. Un incremento de la demanda de los servicios ofertados por los "polleros" debido a la militarización de la frontera tornó esta actividad más lucrativa. Como consecuencia, el número de "coyotes" creció de modo geométrico en Tamaulipas, y éstos ahora, para conservar un mayor número de clientes, se ven obligados a mantener competitivas sus tarifas.

Por otra parte, es necesario puntualizar que el término "cruzar la frontera" no es unívoco. No tiene la misma dificultad cruzar el río Bravo que llegar a Corpus Christi o Houston (Spener, 2001:231). En este sentido, una elevación de las tarifas de los "coyotes" en los últimos años también aparece relacionada con un debilitamiento de la ruta migratoria que llegaba hasta el valle de Texas, y un robustecimiento de las rutas migratorias que llegan hasta el sureste y la región centro-norte de los Estados Unidos. Es decir, parte de la subida de las tarifas de los "coyotes" se debe a un alargamiento de las rutas. Incluso en una fecha tan cercana como el año 2006, Roberto dijo haber pagado únicamente 2500 pesos por cruzar el río Bravo, cuando muchos de los que llegaron hasta Houston afirmaron haber pagado sumas cercanas a los 2 mil dólares.

\section{Rutas migratorias más complejas y estancias más largas en Estados Unidos}

Los jornaleros tamaulipecos indocumentados que emigran a Estados Unidos siguen o bien una ruta corta que llega hasta el valle de Texas, o bien un trayecto más largo que se desplaza a través de dos ramificaciones. La más importante se desliza por el sureste estadounidense. Pasa por Luisiana, Alabama, Georgia, Florida, Tennessee y Carolina del Norte, y llega hasta Virginia y Nueva Jersey. La otra ramificación, de menor envergadura, llega hasta el centro-norte de los Estados Unidos, principalmente a Missouri, Michigan y Minnesota. Washington, en el extremo nororiental, es un área receptora de numerosos jornaleros tamaulipecos que van a trabajar en la manzana por medio de visas H-2A; sin embargo, hay pocos trabajadores indocumentados que se aventuran a llegar hasta este estado (véase cuadro 7). 
Cuadro 7. Lugares donde emigraron los jornaleros tamaulipecos entrevistados

\begin{tabular}{|c|c|c|c|c|c|c|c|c|}
\hline \multirow{3}{*}{ Estado } & \multicolumn{6}{|c|}{ Grupo de edad } & \multicolumn{2}{|c|}{ Total } \\
\hline & \multicolumn{2}{|c|}{$<30$} & \multicolumn{2}{|c|}{$30-45$} & \multicolumn{2}{|c|}{$>45$} & & \\
\hline & Casos & $\%$ & Casos & $\%$ & Casos & $\%$ & Casos & $\%$ \\
\hline Texas & 6 & 38 & 12 & 67 & 11 & 69 & 29 & 58 \\
\hline Florida & 2 & 13 & 7 & 39 & 4 & 25 & 13 & 26 \\
\hline Carolina del Norte & 5 & 31 & 5 & 28 & 2 & 13 & 12 & 24 \\
\hline Georgia & 3 & 19 & 3 & 17 & 4 & 25 & 10 & 20 \\
\hline Virginia & 1 & 6 & 4 & 22 & 1 & 6 & 6 & 12 \\
\hline Michigan & & & 3 & 17 & & & 3 & 6 \\
\hline Minnesota & 2 & 13 & & & 1 & 6 & 3 & 6 \\
\hline Missouri & & & 1 & 6 & 2 & 13 & 3 & 6 \\
\hline Tennessee & & & 1 & 6 & 2 & 13 & 3 & 6 \\
\hline Luisiana & & & 1 & 6 & 1 & 6 & 2 & 4 \\
\hline Nueva Jersey & & & & & 2 & 13 & 2 & 4 \\
\hline Alabama & 1 & 6 & & & & & 1 & 2 \\
\hline Arkansas & & & & & 1 & 6 & 1 & 2 \\
\hline Dakota del Sur & & & & & 1 & 6 & 1 & 2 \\
\hline Iowa & 1 & 6 & & & & & 1 & 2 \\
\hline Nueva York & 1 & 6 & & & & & 1 & 2 \\
\hline Oklahoma & & & & & 1 & 6 & 1 & 2 \\
\hline Washington & & & 1 & 6 & & & 1 & 2 \\
\hline
\end{tabular}

Fuente: Elaboración propia a partir de una muestra intencional.

El valle de Texas es la región de Estados Unidos más cercana a Tamaulipas; como consecuencia, es la zona más accesible. Además, esta área se caracteriza por un alto nivel de interdependencia transfronteriza con Tamaulipas en el ámbito cultural, social y económico (Spener, 2001:210). Sin embargo, las condiciones sociolaborales imperantes en la agricultura tejana son especialmente severas. La mayor parte del empleo agrario es irregular y los salarios son más bajos que en otras áreas del país debido a la abundancia de trabajadores indocumentados que cruzan diariamente la frontera. ${ }^{13}$

${ }^{13}$ Por ejemplo, un pizcador de naranja indocumentado, que apenas gana 5 dólares la hora en el valle de Texas, puede ganar más de 9 dólares en lugares como Florida. 
Hasta hace una década el valle de Texas presentaba el atractivo de ser un mercado de trabajo cercano a Tamaulipas, por lo que muchos jornaleros tamaulipecos cruzaban la frontera por sí mismos, trabajaban allí unos meses y luego regresaban a sus comunidades de origen. Sin embargo, en el marco de una progresiva militarización de la frontera y de una mayor criminalización de la migración irregular, el atractivo de esta primera ruta migratoria ha disminuido. En el cuadro 7 se puede apreciar que aunque Texas sigue siendo el principal lugar de destino de los trabajadores rurales indocumentados tamaulipecos, el porcentaje de jóvenes que trabajaron en Texas es muy inferior a la proporción de jornaleros de los otros grupos de edad que obtuvieron empleo en este estado. Los bajos salarios pagados en el sur de Texas no compensan las elevadas tarifas de los "polleros". Actualmente, cuando el inmigrante asume el riesgo de cruzar la frontera espera obtener un mayor retorno económico que el proporcionado por el mercado de trabajo fronterizo. Por lo tanto, el valle de Texas se torna la mayor parte de las ocasiones en una zona de paso. María señalaba:

San Isidro está aquí cerquita. Casi todos los "mojados" pasan por ahí y piden trabajo para con lo que les paguen seguir internándose hacia el norte, que es donde les conviene porque el trabajo es más bien pagado.

En la actualidad la mayor parte de los jornaleros indocumentados tamaulipecos se adentran hacia rutas más largas, que llegan hasta el centro-norte y el sureste de los Estados Unidos, y sus estancias se prolongan cada vez más, como consecuencia de una elevación sustancial del costo económico y social de cruzar la frontera. Según Javier:

Las personas que van se quedan a trabajar por varias temporadas; es decir, algunos años, como unos cuatro o cinco, para que costee el viaje y la pagada, porque no tiene caso arriesgarse para estar allá dos años.

Esta misma idea aparecía expresada por Celestino:

Ahora pues está más difícil ir de ilegal, por eso el que logra entrar dura hasta cuatro, cinco o más años para regresar. 
En ocasiones los jornaleros indocumentados tamaulipecos siguen una ruta migratoria que se desplaza de Florida a Virginia haciendo un intermedio en Carolina del Norte. Durante los meses de diciembre a abril hay trabajo abundante en Florida en la pizca de la naranja. En los meses de abril a julio se acrecienta la demanda de mano de obra en las plantaciones tabaqueras de Carolina del Norte. Finalmente, entre septiembre y noviembre abunda el trabajo en la pizca de la manzana en Virginia. La ruta centro-norte, que se desplaza principalmente a Missouri, Michigan y Minnesota, presenta un menor atractivo debido a las condiciones climáticas, que divergen enormemente del clima cálido tamaulipeco.

\section{La pérdida de atractivo de la inmigración irregular y el creciente interés en el programa H-2A de trabajadores huéspedes}

Un control más riguroso de la frontera ha desincentivado la emigración irregular. Jornaleros jóvenes con experiencia de haber emigrado previamente sin documentos, se muestran cada vez más reacios a emigrar. Los entrevistados expresaron un claro interés por emigrar, sin embargo, el mayor riesgo que acarrea cruzar la frontera de modo irregular y el endurecimiento de las penas contra los indocumentados se convierten en factores represores de este deseo. José decía:

\footnotetext{
A veces me entra la idea de hacerlo [cruzar la frontera] aunque me agarren; pero me rajo cuando pienso a la hora de que me encierren, porque antes no lo hacían, o por lo menos no dejaban tanto tiempo encerrado como lo hacen ahora; ya está muy duro poder pasar.
}

Asimismo, Zúñiga, cuando se le preguntó si iba a regresar a Estados Unidos, respondió:

A lo mejor ya no se puede, por lo mismo de que ahora la ley es más dura; de que quiero ir, sí. 
Igualmente, otros entrevistados de mayor edad, que emigraron a Estados Unidos décadas atrás, señalaban que la gente joven ya no se arriesgaba a cruzar la frontera como en años anteriores.

Esta misma idea aparece confirmada por los "polleros". Éstos señalan que el endurecimiento de los controles fronterizos ha desincentivado la emigración subrepticia, de modo que el número de clientes ha sufrido una merma. Según Jorge:

Hoy hay menos gente que va [...] Eso también es un problema porque cada día hay menos clientes.

La mayor dificultad para reclutar indocumentados aparecía expresada del siguiente modo por Marcos:

Sí es difícil, porque vas con la esperanza de que hay, vas a lo seguro, y luego te dicen: fíjate compa que no, ando trabajando bien y pues no se hace este trato, y tienes que irte a otro lugar a buscar.

Por otra parte, la precaria situación económica de muchas familias rurales tamaulipecas debido a problemas de subempleo, desempleo y falta de oportunidades económicas, unido a unos salarios más atractivos en Estados Unidos, implica que un segmento importante de los jóvenes rurales tamaulipecos esté dispuesto a correr el riesgo de cruzar la frontera sin papeles (Izcara Palacios, 2006:119). Como explicaba Ejidio:

Tienes cada vez que pagar más, ahorita hasta dos mil dólares, y como sale caro, a veces te dan ganas de rajarte; pero de pensar en tus hijos y viendo que tu casa va para arriba, te entran energías y te vuelves a ir sin importarte los riesgos y cuánto pagas.

La mayor dificultad de emigrar sin papeles hace que los jornaleros tamaulipecos busquen cada vez con mayor ahínco integrarse en el programa de visas H-2A de trabajadores huéspedes, que les permite 
trabajar de modo temporal en Estados Unidos. ${ }^{14}$ Entre los años 1998 y 2006 el número de visas H-2A aprobadas en el Consulado de Estados Unidos en Monterrey a trabajadores de Tamaulipas se incrementó de 753 a 1885 . Esto convierte a Tamaulipas en una de las entidades federativas que recibe más visas temporales para la realización de labores agrarias. Para los empleadores estadounidenses, que deben pagar los gastos de transporte, resulta más económico contratar a un trabajador de la frontera que a uno del interior. Además, los jornaleros tamaulipecos tienen experiencia en la realización de actividades muy demandantes, como la pizca de la naranja o la zafra de la caña, que guardan cierta similitud con las labores que tendrán que realizar en Estados Unidos. Sin embargo, la oferta de empleo es muy inferior a la demanda. Por lo tanto, los empresarios agrarios estadounidenses disponen de un amplio abanico de trabajadores rurales de donde elegirán a los más aptos (Izcara Palacios y Andrade Rubio, 2008:375). Como resultado de un deseo de trabajar en el país del norte y una pérdida de atractivo de la inmigración irregular, la competencia por los contratos H-2A se ha incrementado. Cada año es mayor el número de jornaleros que se enlistan con los contratistas locales ${ }^{15}$ con la esperanza de obtener un contrato temporal que les permita trabajar legalmente en los Estados Unidos. Eduardo decía:

Está enlistando la gente muy temprano, porque ahorita ya hay mucha competencia.

Aquellos trabajadores que tienen una mayor probabilidad de ser contratados son los jornaleros que participaron en años anteriores en el programa, cumplieron su contrato y no protagonizaron ninguna queja o altercado, y además, son jóvenes, fuertes y trabajadores. Sin embargo, ningún trabajador tiene la seguridad de volver a aparecer

${ }^{14} \mathrm{El}$ programa $\mathrm{H}-2 \mathrm{~A}$ de trabajadores agrarios temporales, que permite importar trabajadores foráneos a aquellos empleadores que pueden demostrar una carencia de mano de obra en su región, fue autorizado en 1986 en el marco de la enmienda a la Ley de Inmigración y Naturalización.

${ }^{15}$ Los jornaleros tamaulipecos son contratados a través de contratistas locales, que son empleados por contratistas laborales estadounidenses (generalmente asociaciones de productores). 
en la lista la siguiente temporada. Fidel, que llevaba trabajando más de 10 años en Carolina del Norte, afirmaba:

Uno no está seguro, porque pues así es en todo. Uno está con la esperanza de que le hablen, verdad, porque pues si no ya se amoló.

Aquellos que muestran un comportamiento reivindicativo, pierden días de trabajo por enfermedad, o no manifiestan un desempeño laboral adecuado serán despedidos o reemplazados durante la siguiente temporada.

Los jornaleros que no pueden tener acceso a una visa de trabajadores huéspedes, optarán por cruzar la frontera de modo irregular. Pero únicamente se van de "mojados" cuando pierden la esperanza de ser contratados, bien porque fueron detenidos por las autoridades migratorias y cualquier petición de visa de trabajo será automáticamente denegada, o bien porque los contratistas nunca los inscriben en las listas. Como señalaba Álvaro:

De mojado ya no voy, porque es más seguro ir contratado. Pero pues si un día tengo mucha necesidad y veo que contratado no se puede ir, pues ni modo, me voy de "mojado".

Actualmente está decreciendo el número de trabajadores rurales tamaulipecos que se animan a cruzar la frontera sin papeles. Sin embargo, los empresarios agrarios estadounidenses siguen demandando mano de obra indocumentada. ${ }^{16}$ Por lo tanto, para corregir este déficit de indocumentados, durante los últimos años los empleadores han activado el mercado de trabajadores irregulares a partir de un esfuerzo por reclutarlos en sus lugares de origen. David Spener (2001, 2004), en diversos trabajos sobre el contrabando de indocumentados en la frontera de Texas con el nordeste de México, ha subrayado la importancia del tráfico en pequeña escala, conducido por "polleros"

${ }^{16}$ Basta leer las estadísticas oficiales para descubrir que más de la mitad de los trabajadores agrarios empleados en Estados Unidos no tienen documentos. 
que forman parte de la corriente migratoria y que en ocasiones realizan esta actividad a tiempo parcial.

Estos "polleros", que trafican a pequeña escala, proceden de una comunidad próxima al lugar de residencia de los indocumentados, y muchas veces están unidos a ellos por redes familiares y de compadrazgo. Su perfil es el de jornaleros que años atrás cruzaron la frontera sin documentos para trabajar durante un periodo prolongado (de 2 a 4 años) para un empleador que reconoció su valía. Más tarde regresaron a Tamaulipas, pero después de pasar aquí un tiempo (de 1 a 3 años), debido a problemas económicos, decidieron volver con ese mismo empresario agrario. Aunque esta vez no lo hicieron solos; debido a que tenían la experiencia de haber cruzado la frontera y conocían los entresijos del cruce fronterizo, se convirtieron en líderes de un reducido número de familiares, amigos o paisanos (de 3 a 5 personas) que también querían trabajar en el país vecino. Una vez en Estados Unidos, su antiguo empleador no únicamente los recibió con los brazos abiertos, sino que los alentó a seguir desarrollando esta actividad en el futuro. En algunos casos dejaron de trabajar como jornaleros para dedicarse únicamente al tráfico de indocumentados, una actividad más lucrativa. En otros casos, continuaron trabajando como jornaleros, pero regresan a Tamaulipas cuando su empleador necesita mano de obra. Generalmente estos últimos reciben un salario fijo de su empleador (que varía entre 1500 y 5 mil dólares por cruce). Más tarde, será el patrón el que descontará al indocumentado una porción de su salario para compensar los gastos del viaje, que muchas veces ascienden a más de 2 mil dólares. ${ }^{17}$

También es necesario señalar que no toda la frontera presenta la misma porosidad. En Tamaulipas el nivel de vigilancia es más bajo que en otras áreas, y el clima no es tan extremo. Además, la población de Texas es más cooperativa y tolerante con el indocumentado que la de California, Arizona o Nuevo México. Como consecuencia, en los últimos años empleadores de lugares tan lejanos como el noroeste de los Estados Unidos, han comenzado a reclutar jornaleros tamaulipecos.

${ }^{17}$ En estos casos el patrón debe pagar también a varios intermediarios que facilitan que el pollero realice su labor de modo exitoso. 
Jesús, el yerno de un empresario agrario de Oregón, decía que ahora estaba reclutando jornaleros tamaulipecos porque

[...] donde no hay vigilancia y es fácil es por Texas y Tamaulipas; de Coahuila para allá es más peligroso, por el clima, y la gente es más mala, no te ayuda si te ven batallando, y los de Texas sí. En Texas hay mucho mexicano nacionalizado.

\section{Un control sesgado de la inmigración ilegal}

En Estados Unidos el incentivo básico de la inmigración subrepticia es la oferta de empleos para trabajadores sin documentos (Andreas, 1999:603). Por lo tanto, resulta paradójico que una mayor vigilancia de la frontera, lejos de ir unida a un incremento del monitoreo en los lugares de trabajo, haya ido acompañada de una reducción de las investigaciones practicadas a los empleadores (Smith-Nonini, 2002:64; Cornelius, 2007:268; Spener, 2001:14; Andreas, 2001:6).

Los entrevistados tienen la impresión de que el control fronterizo del flujo de indocumentados está sesgado. Éstos conocen que las autoridades migratorias disponen de una tecnología muy avanzada de vigilancia de la frontera; por lo tanto, piensan que si la patrulla fronteriza quisiese sellarla, podría hacerlo. Ejidio señalaba:

Tienen cuidando todo lo que es el río con cámaras, aviones, con todo; así que saben por dónde pasa uno, cuánta gente pasa a diario, a unos agarran, a otros no agarran, y así que ellos tienen que dejar pasar gente. Yo digo que los dejan pasar, porque si ellos no quisieran no dejaban pasar a nadie.

Según este jornalero, una parte mayoritaria de los trabajadores indocumentados no sería acosada por el Servicio de Inmigración (INS por sus siglas en inglés), mientras un pequeño porcentaje, los más desafortunados, sí serían detenidos y expulsados del país. Por lo tanto, traspasar la frontera sería más bien una cuestión de azar. Nelson hacía alusión a esta misma idea, y relataba del siguiente modo la facilidad con la que él cruzaba la frontera: 
Cómo es que se cruza el río si hay cámaras y mucha vigilancia, tanto aquí como allá. Pero bueno, eso lo arregla mi patrón, ${ }^{18}$ a mí sólo me dice: yo necesito gente, tráetela, y la llevo, él es el que hace los arreglos.

En otras entrevistas, la porosidad de la frontera es atribuida a la falta de diligencia de las autoridades migratorias estadounidenses en el desempeño de su actividad. En este sentido, Cesáreo afirmaba:

Las cámaras funcionan todo el tiempo, pero la raza pasa aunque los mire la cámara, y el chiste es cruzar, ya de aquel lado uno se va escondiendo, o a veces pues les da flojera a los de migración, y los dejan que se vayan.

La mayor parte de los entrevistados cree que los campos donde trabajan no son objeto de escrutinio por parte de las autoridades migratorias (véase cuadro 8). Las explotaciones agrarias son definidas como una especie de fortalezas donde los indocumentados se encuentran protegidos. Algunos de los trabajadores tamaulipecos empleados en el valle de Texas describían cómo la patrulla fronteriza llegaba, tanto por carretera como por aire, hasta los campos de naranja o sandía donde ellos trabajaban, los observaba y luego pasaba de largo sin hacer preguntas. Roberto, que trabajó en el condado de Hidalgo (Texas) en el año 2007, decía:

No te hacía nada la migra, por eso a veces nos miraban y no nos hacían nada [...] No te hace nada, te respeta porque andas en horas de trabajo.

Asimismo, Héctor, que estuvo empleado en el condado de Starr (Texas) en el año 2005, señalaba:

Pasaban por la entrada de los ranchos, y en las carreteras; incluso en los helicópteros pasaban así encima de la parcela en donde estábamos trabajando, pero ellos nunca se bajaban a revisar.

${ }^{18} \mathrm{El}$ propietario de un rancho ganadero de San Antonio (Texas). 
Aquellos jornaleros de más edad, que emigraron décadas atrás, aludían en términos jocosos a la abundancia de trabajadores indocumentados en las huertas y a la inexistencia de registros por parte de las autoridades migratorias. Juan, que participó en el contrato bracero entre los años 1958 y 1964, y después, entre 1968 y 1986, cruzó la frontera en tres ocasiones para trabajar en Texas, Carolina del Norte, Nueva Jersey y Missouri, señalaba:

Nunca fueron los de la migra ahí donde trabajábamos; si no imagínese, pues ahí habíamos puros ilegales.

Existe una opinión general de que las autoridades migratorias no persiguen a aquellos inmigrantes que están trabajando.

La seguridad que encuentra el jornalero indocumentado en el lugar de trabajo contrasta con un mayor acoso y riesgo de ser interceptado por las autoridades migratorias durante sus espacios de ocio -cuando pasean por las calles o entran en algún establecimiento- (véase cuadro 8). Apolonia, que cruzó la frontera 12 veces entre los años 1986 y 2002 para trabajar como jornalera, principalmente en Florida, pero también en Texas, Nueva Jersey y Missouri, expresaba esta idea de la siguiente forma:

No tienen ellos autorización de meterse a sacar a uno de donde anda trabajando; ya, si lo agarran a uno en la calle, pues es lógico que sí.

Como consecuencia, la mayor parte del tiempo permanecen recluidos en los campos agrícolas. Además, los empleadores son reacios a permitir que los jornaleros indocumentados salgan de los ranchos. De este modo minimizan el riesgo de perder trabajadores, que serían aprehendidos si son detectados por las autoridades migratorias. Expresiones como: "El patrón no quería que fuéramos al pueblo"; "el patrón siempre nos recomendó que no anduviéramos mucho en el pueblo"; o "el patrón no quería que saliéramos" abundan en las entrevistas.

Tres de los 50 jornaleros indocumentados entrevistados afirmaron que las autoridades migratorias estadounidenses eran corruptas y aceptaban sobornos a cambio de permitir a los empresarios agrarios 
Cuadro 8. Opinión de los entrevistados sobre el control de los trabajadores migratorios indocumentados.

\begin{tabular}{|c|c|c|c|c|}
\hline Grupos de edad & $<30$ & $30-45$ & $>45$ & Total \\
\hline Número total de entrevistados & 16 & 18 & 16 & 50 \\
\hline $\begin{array}{l}\text { Manifestó que los campos de labor no } \\
\text { son escrutados por las autoridades } \\
\text { migratorias. }\end{array}$ & 9 & 12 & 10 & 31 \\
\hline $\begin{array}{l}\text { Señaló que los jornaleros } \\
\text { indocumentados únicamente son } \\
\text { perseguidos por el INS cuando se } \\
\text { encuentran ociosos fuera de las } \\
\text { explotaciones agropecuarias. }\end{array}$ & 6 & 9 & 4 & 19 \\
\hline $\begin{array}{l}\text { Expresó que las autoridades } \\
\text { migratorias son corruptas y aceptan } \\
\text { sobornos de los empleadores. }\end{array}$ & & 2 & 1 & 3 \\
\hline $\begin{array}{l}\text { Afirmó que los empleadores conocían } \\
\text { con antelación cuándo habría una } \\
\text { inspección del INS. }\end{array}$ & 1 & 4 & 2 & 7 \\
\hline
\end{tabular}

Fuente: Elaboración propia a partir de una muestra intencional.

dar empleo a inmigrantes ilegales (véase cuadro 8). ${ }^{19}$ Aunque únicamente $6 \%$ de los integrantes de la muestra hizo esta observación, éste es un dato remarcable, ya que indica que algunos de los jornaleros tamaulipecos que trabajan sin documentos en los Estados Unidos han sido testigos de actos de corrupción que involucran a las autoridades migratorias estadounidenses. María, esposa de un empresario agrario del sur de Texas, señalaba en una entrevista que su marido, debido a que tenía una relación de parentesco con el sheriff del condado, era alertado cada vez que las autoridades migratorias iban a registrar su explotación en busca de trabajadores indocumentados. Esta idea aparecía apoyada por el testimonio de Javier, que decía:

${ }^{19}$ El INS ha sido subrayado como la agencia gubernamental estadounidense más vulnerable a la corrupción (Andreas, 1998:83 y 1999:601). 
Los rancheros ya están arreglados con los sheriffs de los condados para que los dejen trabajar con personas que no tienen papeles, y cuando va a haber redada avisan para que escondan a la gente.

Asimismo, Ignacio remarcaba esto:

Son gente que va a trabajar y no se les molesta porque el patrón ya está arreglado; por eso, no hay necesidad de eso, ${ }^{20}$ la migra ya sabe.

Un 14\% de los entrevistados confirmó las anteriores aseveraciones al señalar que siempre que había una revisión de inmigración en el rancho donde trabajaban eran avisados de antemano (véase cuadro 8). En algunas explotaciones agrarias se utiliza un código que conocen todos los trabajadores, como por ejemplo un tono musical, para advertirles de la existencia de una inspección del Servicio de Inmigración. Así, cuando escuchan la señal, inmediatamente abandonan la actividad que están realizando para esconderse. Como relataba Fernando, algunos ranchos cuentan incluso con espacios encubiertos donde los jornaleros ilegales pueden ocultarse durante el tiempo que dura la inspección. Cabe mencionar que los jornaleros jóvenes, que pensaban volver a cruzar la frontera, se mostraban algo más reacios a tratar esta temática en las entrevistas.

\section{Conclusiones}

La militarización de la frontera obedece al esparcimiento de un sentimiento antiinmigración, que se acentúa en la década de los noventa como consecuencia de un incremento del número de indocumentados procedentes principalmente de México, y se consolida aún más con los sucesos del 11 de septiembre. El flujo migratorio irregular obedece a la demanda de mano de obra barata y esforzada en sectores como el agrario. Sin embargo, la política migratoria estadounidense ha hecho

${ }^{20}$ Proporcionar documentos falsos a los trabajadores. 
oídos sordos a este hecho y sigue centrada en reforzar la seguridad fronteriza.

Esta política bipolar que criminaliza a los indocumentados pero permite que sean empleados es inadecuada. Por una parte, obliga a los inmigrantes a contratar los costosos servicios de "polleros" experimentados para poder esquivar la vigilancia fronteriza. Por otra, las autoridades migratorias les permiten trabajar libremente en el campo; de modo que las explotaciones agrícolas se convierten en una especie de campos de reclusión, ya que mientras permanecen allí se encuentran protegidos, pero si salen se exponen a ser detenidos y deportados.

Durante los últimos años, al mismo tiempo que los esfuerzos por impermeabilizar la frontera se han incrementado, los recursos destinados a detener el empleo de mano de obra indocumentada han disminuido. Esto impide el desarrollo de una política migratoria racional que impulse la regularización de aquellos trabajadores que no tienen documentos pero son demandados por el mercado laboral. Sectores como la agricultura no demandarán una regularización de trabajadores foráneos mientras se les permita emplear mano de obra indocumentada. La indiferencia de las autoridades migratorias ante el empleo de indocumentados contribuye a crear una falsa apariencia de que el mercado laboral estadounidense no necesita de la regularización de millones de migrantes que utilizan documentación falsa para trabajar, y alimenta un sentimiento antiinmigración basado en el axioma de que los indocumentados son gente que cruzó la frontera huyendo del hambre para arribar a una economía que puede prescindir de ellos.

\section{Bibliografía}

Andrade Rubio, K.L. (2008), “Intermediación laboral, migración y exclusión social: los pizcadores de naranja en Tamaulipas", Caleidoscopio, 12 (23), pp. 101-114.

Andreas, P. (1996), "Us-Mexico: Open Markets, Closed Border", Foreign Policy, 103, pp. 51-69. 
ESTUDIOS FRONTERIZOS, VOL. 10, NÚM. 20, JULIO-DICIEMBRE 2009

Andreas, P. (1998), "Smuggling Wars: Law Enforcement and Law Evasion in a Changing World", Transnational Organized Crime, 4 (2), pp. 75-90.

(1999), "The Escalation of US Immigration Control in the PostNAFTA Era", Political Science Quarterly, vol. 113, núm. 4, pp. 591615.

(2001), Border Games. Policing the us-Mexico Divide, Ithaca, Cornell University Press. (2003), A Tale of Two Borders: The US-Mexico and US-Canada Lines after 9-11, The Center for Comparative Immigration Studies, University of California, San Diego, Working Paper 77.

Arroyo Alejandre, J., A. De León Arias y M.B. Valenzuela Varela (1991), Migración rural hacia Estados Unidos. Un estudio regional en Jalisco, México, Consejo Nacional para la Cultura y las Artes.

Cabrera, E. (2007), "Migración: inaceptable el unilateralismo", en E. Cabrera (ed.), Desafios de la migración. Saldos de la relación MéxicoEstados Unidos, México, Planeta.

Corona, R. y R. Tuirán (2001), “La migración internacional desde y hacia México", en J. Gómez y C. Rabell, La población de México. Tendencias y perspectivas sociodemográficas hacia el siglo XXI, MéxiCo, FCE.

Corona Vázquez, R. (2008), “Características, alcances y limitaciones de la información estadística sobre migraciones en el interior, desde y hacia la República Mexicana", en B. Figueroa Campos, El dato en cuestión. Un análisis de las cifras sociodemográficas, México, El Colegio de México.

Cornelius, W.A. (2007), “Una década experimentando con una política. Control de la inmigración no deseada”, en E. Cabrera (ed.), Desafíos de la migración. Saldos de la relación México-Estados Unidos, México, Planeta.

Coyne, I.T. (1997), "Sampling in Qualitative Research. Purposeful and Theoretical Sampling, Merging or Clear Boundaries?", Journal of Advanced Nursing, núm. 26, pp. 623-630.

Green, R. (2007), “De fantasmas y otras fantasías”, en E. Cabrera (ed.), Desafíos de la migración. Saldos de la relación México-Estados Unidos, México, Planeta. 
Hanson, G.H., R. Robertson y A. Spilimbergo (2002), “Does Border Enforcement Protect US Workers from Illegal Immigration?", Review of Economics and Statistics, 84 (1), 73-92.

Izcara Palacios, S.P. (2006), Infraclases rurales. Los trabajadores eventuales agrarios de Tamaulipas (México) y Andalucía (España), México, Plaza y Valdés. (2007), Introducción al muestreo, México, Miguel Ángel Porrúa. (2009a), Análisis demográfico de Tamaulipas, México, Plaza y Valdés. (2009b), "Privación relativa y emigración: el caso tamaulipeco", Migraciones Internacionales, vol. 5, núm. 1, pp. 7-33.

y K.L. Andrade Rubio (2006), “Vivir en el fondo. Infraclases rurales y pizca de naranja en Tamaulipas", Trayectorias, año VIII, núm. 20-21, pp. 163-172.

y K.L. Andrade Rubio (2007), “Subempleo e irregularidad laboral: los jornaleros tamaulipecos", Sociología del Trabajo, núm. 59, pp. 61-78.

y K.L. Andrade Rubio, (2008), “Los jornaleros tamaulipecos y los déficits del programa H-2A de trabajadores huéspedes", en R. Pérez Redondo, A. García Manso y M. Escribano Castellanos (eds.), Sociedad, Consumo y Sostenibilidad, Toledo, ACMS.

Marroni, M. G. y G. Alonso Meneses (2006), “El fin del sueño americano. Mujeres migrantes muertas en la frontera México-Estados Unidos", Migraciones Internacionales, vol. 3, núm. 3, pp. 5-30.

Martin, P. (1990), "Harvest of Confusion: Immigration Reform and California Agriculture", International Migration Review, vol. 24, núm. 1, pp. 105-131.

Orrenius, P.M. y M. Zavodny (2001), Do Amnesty Programs Encourage Illegal Immigration? Evidence from IRCA, Federal Reserve Bank of Dallas, Research Department Working Paper 0103.

Pérez Duperou, G. H. (2007), “'La política migratoria de Estados Unidos después del 11 de septiembre. Reforzamiento de la seguridad fronteriza", en C. Imaz Bayona (coord.), ¿Invisibles? Migrantes internacionales en la escena política, México, Universidad Nacional Autónoma de México.

Reyes, B.I. (2001), "Immigrant Trip Duration: The Case of Immigrants from Western Mexico", International Migration Review, vol. 35, núm. 4, pp. 1185-1204. 
Reyes, B.I. (2004) “Changes in Trip Duration for Mexican Immigrants to the United States", Population Research and Policy Review, vol. 23, núm. 3, pp. 235-257.

Smith-Nonimi, S. (2002), "Nadie sabe, nadie supo: el programa federal H2A y la explotación de mano de obra mediada por el Estado", Relaciones, núm. 90, vol. XXIII, pp. 56-86.

Spener, D. (2001), “El contrabando de migrantes en la frontera de Texas con el nordeste de México: mecanismo para la integración del mercado laboral de América del Norte", Espiral, Estudios sobre Estado y Sociedad, núm. 21, pp. 201-247.

(2004), "Mexican Migrant-Smuggling: A Cross-Border Cottage Industry", Journal of Internacional Migration and Integration, vol. 5, núm. 3, pp. 295-320.

Stephen, L. (2002), “Globalización, el Estado y la creación de trabajadores indígenas 'flexibles': trabajadores agrícolas mixtecos en Oregón”, Relaciones, núm. 90, vol. XXIII pp. 89-114.

Tuirán, R. (2006), “La reforma migratoria pendiente", Migraciones Internacionales, vol. 3, núm. 4, pp. 161-174.

(2007), “Migración, fantasmas y reforma. La migración mexicana a los Estados Unidos: los retos del presente y del futuro", en E. Cabrera (ed.), Desafíos de la migración. Saldos de la relación MéxicoEstados Unidos, México, Planeta.

Valdivia Durán, A. (2001), "La migración internacional aguascalentense", en E. Herrera Muñoz, De nidos llenos a nidos vacíos: entre aves migratorias, México, CIEMA.

Velasco Ortiz, L. (2002), “Agentes étnicos transnacionales: las organizaciones de indígenas migrantes en la frontera México-Estados Unidos", Estudios Sociológicos, vol. XX, núm. 59, pp. 335-369.

Verduzco Igartúa, G. (1995), “La migración mexicana a Estados Unidos: recuento de un proceso histórico", Estudios Sociológicos, vol. XIII, núm. 39, pp. 573-594.

Zúñiga, E. y P. Leite (2007), “Frontera, migración, impactos. Los procesos contemporáneos de la migración mexicana a Estados Unidos", en E. Cabrera (ed.), Desafíos de la migración. Saldos de la relación México-Estados Unidos, México, Planeta. 
Simón Pedro IzCARA PALACIOS/Militarización DE LA FRONTERA

Relación de entrevistas que aparecen citadas en el texto

Alejandro Entrevista realizada en el municipio de San Carlos (Tamaulipas) en agosto de 2008 a un jornalero de 27 años de edad que emigró a Estados Unidos con una visa H-2A.

Alfonso Entrevista realizada en el municipio de Abasolo (Tamaulipas) en noviembre de 2008 a un jornalero de 40 años de edad que emigró a Estados Unidos con una visa H-2A.

Álvaro Entrevista realizada en el municipio de Guémez (Tamaulipas) en noviembre de 2008 a un jornalero de 34 años de edad que emigró a Estados Unidos con una visa H-2A.

Apolonia Entrevista realizada en el municipio de Villagrán (Tamaulipas) en octubre de 2007 a una jornalera de 46 años de edad que emigró a Estados Unidos sin documentos.

Celestino Entrevista realizada en el municipio de Jaumave (Tamaulipas) en enero de 2008 a un jornalero de 64 años de edad que emigró a Estados Unidos sin documentos.

Cesáreo Entrevista realizada en el municipio de Tula (Tamaulipas) en mayo de 2008 a un jornalero de 39 años de edad que emigró a Estados Unidos sin documentos.

Eduardo Entrevista realizada en el municipio de Hidalgo (Tamaulipas) en octubre de 2007 a un jornalero de 40 años de edad que emigró a Estados Unidos con una visa H-2A.

Ejidio Entrevista realizada en el municipio de San Carlos (Tamaulipas) en octubre de 2007 a un jornalero de 43 años de edad que emigró a Estados Unidos sin documentos.

Fernando Entrevista realizada en el municipio de Aldama (Tamaulipas) en noviembre de 2007 a un jornalero de 23 años de edad que emigró a Estados Unidos sin documentos.

Fidel Entrevista realizada en el municipio de Tula (Tamaulipas) en diciembre de 2007 a un jornalero de 46 años de edad que emigró a Estados Unidos con una visa H-2A. 
ESTUDIOS FRONTERIZOS, VOL. 10, NÚM. 20, JULIO-DICIEMBRE 2009

Francisco Entrevista realizada en el municipio de Guémez (Tamaulipas) en abril de 2008 a un jornalero de 49 años de edad que emigró a Estados Unidos con una visa $\mathrm{H}-2 \mathrm{~A}$.

Héctor Entrevista realizada en el municipio de Tula (Tamaulipas) en abril de 2008 a un jornalero de 39 años de edad que emigró a Estados Unidos sin documentos.

Ignacio Entrevista realizada en el municipio de Abasolo (Tamaulipas) en julio de 2008 a un "pollero" de 40 años de edad.

Javier Entrevista realizada en el municipio de Victoria (Tamaulipas) en junio de 2008 a un "pollero" de 34 años de edad.

Jorge Entrevista realizada en el municipio de Victoria (Tamaulipas) en abril de 2008 a un "pollero" de 38 años de edad.

José $\quad$ Entrevista realizada en el municipio de Victoria (Tamaulipas) en octubre de 2007 a un jornalero de 30 años de edad que emigró a Estados Unidos sin documentos.

Jesús Entrevista realizada en el municipio de Mier (Tamaulipas) en enero de 2009 a un "pollero" de 41 años de edad.

Juan Entrevista realizada en el municipio de Jaumave (Tamaulipas) en diciembre de 2007 a un jornalero de 67 años de edad que emigró a Estados Unidos sin documentos.

María Entrevista realizada en el municipio de Jaumave (Tamaulipas) en diciembre de 2007 a una jornalera de 30 años de edad que emigró a Estados Unidos sin documentos.

Marcos Entrevista realizada en el municipio de Jaumave (Tamaulipas) en enero de 2009 a un "pollero" de 38 años de edad.

Nelson Entrevista realizada en el municipio de Hidalgo (Tamaulipas) en junio de 2008 a un "pollero" de 41 años de edad. 
Simón PEdRo IzCARA PALACIOS/Militarización DE LA FRONTERA

Roberto Entrevista realizada en el municipio de Hidalgo (Tamaulipas) en marzo de 2007 a un jornalero de 34 años de edad que emigró a Estados Unidos sin documentos.

Torres Entrevista realizada en el municipio de Victoria (Tamaulipas) en noviembre de 2008 a un jornalero de 33 años de edad que emigró a Estados Unidos con una visa $\mathrm{H}-2 \mathrm{~A}$.

Víctor Entrevista realizada en el municipio de Jaumave (Tamaulipas) en enero de 2008 a un jornalero de 29 años de edad que emigró a Estados Unidos sin documentos.

Zúñiga Entrevista realizada en el municipio de Tula (Tamaulipas) en marzo de 2008 a un jornalero de 29 años de edad que emigró a Estados Unidos sin documentos.

Nota: Algunos de los nombres son seudónimos. 
